\title{
A Cryoscopic Study of the Solubility of Uranium in Liquid Sodium at $97.8^{\circ} \mathrm{C}$
}

\author{
Thomas B. Douglas
}

\begin{abstract}
The equilibrium temperatures, at various stages of melting, of three samples of sodium were measured with a standard deviation of 0.001 degree. One sample contained uranium in compact form, and one contained finely divided uranium. Impurities lowered the freezing points of all the samples by approximately 0.035 degree, but the sodium containing finely divided uranium was found to have a freezing point higher than those of the other two samples by 0.005 degree, an effect that may be due to a partial purification of the sodium by the uranium. After extrapolation to no impurity, the freezing points of the three samples agree within 0.001 degree. Allowing for errors, it is concluded that the solubility of uranium in liquid sodium at $97.8^{\circ} \mathrm{C}$ probably does not exceed 0.05 percent by weight and may actually be many times smaller.
\end{abstract}

\section{Introduction}

One of the most sensitive and convenient methods commonly used to estimate the concentration of a dilute solution is the comparison of its liquidus temperatures (freezing points) with that of the pure solvent, if the solid phases are immiscible. This method was applied in an attempt to estimate the solubility of uranium in liquid sodium at $97.8^{\circ} \mathrm{C}$, the triple point of the latter element. The equilibrium temperatures at intervals from 70- to 100percent completion of fusion of the sodium were observed.

\section{Experimental Procedure}

Three samples were prepared, each containing $6 \frac{1}{2} \mathrm{~g}$ of sodium from a batch that had been purified by distillation. In addition to the sodium, the sample designated as A contained no uranium, sample B contained $2 \mathrm{~g}$ of a solid section of uranium, and sample $\mathrm{C}$ contained $2 \mathrm{~g}$ of finely divided uranium prepared by hydride decomposition. The samples were sealed, by induction welding in an oxygen-free inert atmosphere, in small cylinders of stainless steel type 347. Subsequent tests at room temperature and at $150^{\circ} \mathrm{C}$ indicated leakage through the seals to be no greater than $4 \times 10^{-12} \mathrm{~cm}^{3}$ of helium per second, a rate not taken to indicate a real leak.

The apparatus for the cryoscopic measurements is shown in figure 1. Each sample was suspended by a No. 32 nichrome wire in air inside a vertical furnace, whose core maintained a highly uniform environmental temperature because it was surrounded by a silver pipe $10 \mathrm{in}$. long and of $1 / 2$-in. wall thickness. The temperature of the silver was measured by a platinum resistance thermometer whose ice point remained constant to within an amount equivalent to $\pm 0.0005 \mathrm{deg}$ throughout the measurements. Heat was supplied to the sample at will by a constantan heater imbedded in a goldplated copper jacket that surrounded the sample container at an average distance of 0.002 in. A fourjunction differential thermocouple (chromel $\mathrm{P}$ versus constantan), calibrated in place against freezing sodium, enabled precise measurement of the temperature difference between the silver pipe of the furnace and the sample.

A detailed systematic procedure was followed in an effort to make the systematic errors constant and thereby to secure accurate differences in temperature among the three samples. With the individual runs numbered chronologically, runs 1,5 , and 9 were on sample $A$; runs 2,3 , and 4 were on sample $C$; and runs 6,7 , and 8 were on sample B. Run 10 was on a fourth sample of sodium, taken from a different batch prepared 2 years earlier. Each run was made on a different day.

With the sample in place, the furnace was heated to a temperature at which melting of the sodium would just begin, and was then held at approximately this temperature for the next $3 \mathrm{hr}$. The sample was then heated for separated intervals of time until fusion was clearly complete. Thus at any stage of the fusion process the fraction of the total fusion heat that had entered the sample could be taken as a measure of the fraction of the sodium then present as liquid. After each such interval of heating, the equilibrium temperature was measured in the following way. The temperature of the furnace was held constant (within $\pm 0.0005 \mathrm{deg}$ ) at a temperature no more than $0.003 \mathrm{deg}$ higher or lower than the prevailing sample equilibrium temperature,$^{1}$ until the thermocouple reading appeared to be changing by less than $0.0001 \mathrm{deg} / \mathrm{min}$. This furnace control was accomplished by means of a 0.7 -w variable auxiliary heater inside the silver. When the sodium was all crystalline or all molten, the difference between its temperature and that of the furnace decreased by 15 percent per minute owing to heat conduction through the intervening air spaces. However, during melting the error introduced in this way was negligible because of the large magnitude of the heat of fusion and the ease of maintaining then a small temperature difference.

To each equilibrium temperature found was added $0.012 \mathrm{deg}$, as the thermocouple reading was found to approach $-0.012 \mathrm{deg}$ when the temperatures of its junctions were known to be rapidly approaching

\footnotetext{
${ }^{1}$ Reversal of the sign of this temperature difference was used to prove that the thermocouple read the unbiased relative temperature of the sample.
} 


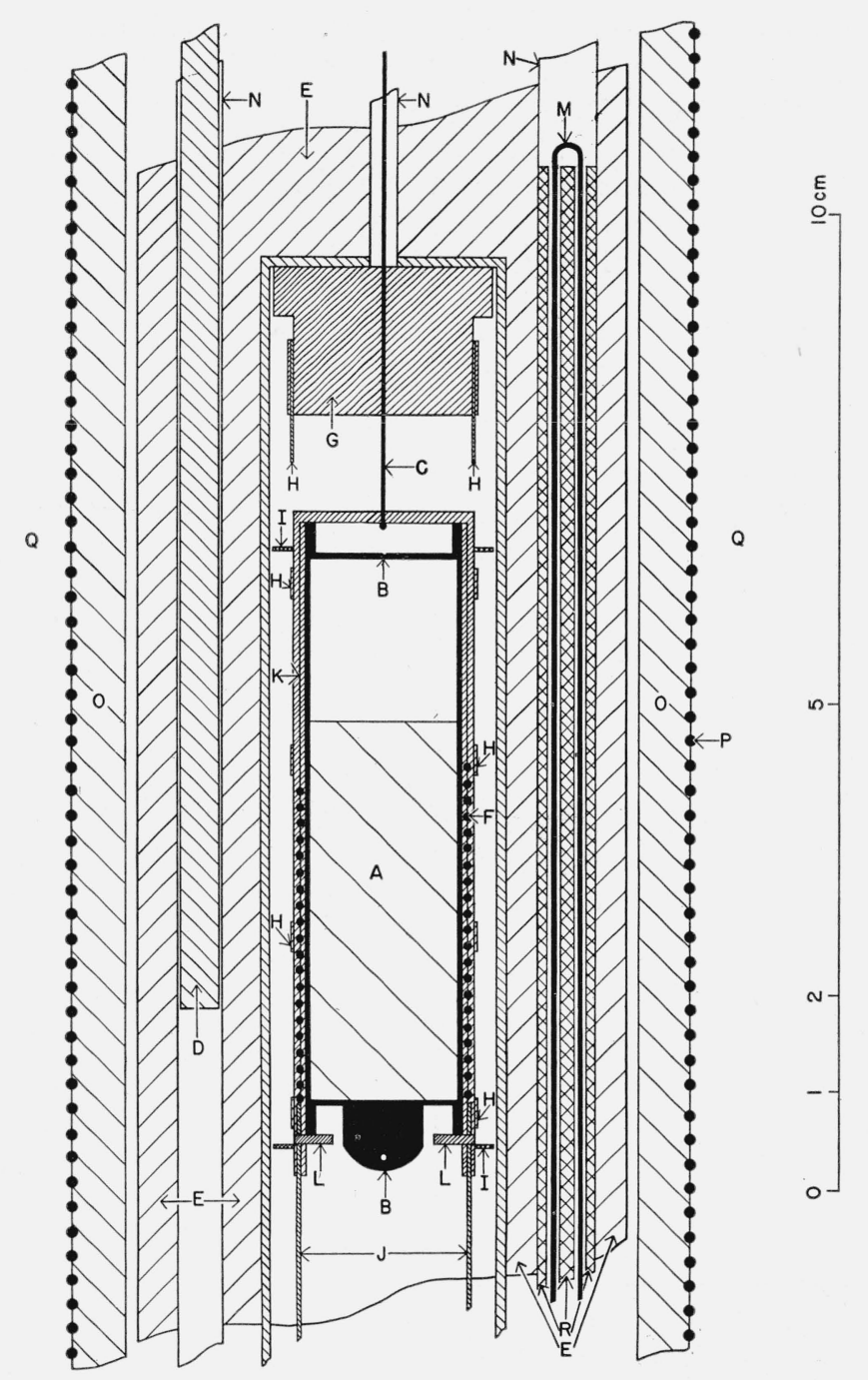

Figure 1. Apparatus for cryoscopic measurements.

A, Sodium sample (with or without uranium); B, sealed container for sample (stainless steel type 347); C, suspension wire (Nichrome V); D, platinum resistance thermometer; E, isothermal jacket (silver); F, heater for sample (glass covered constantan); G, thermocouple reference block (gold-plated copper); $\mathrm{H}$ thermocouple junctions (copper bands or tabs); I, spacers (nichrome V wire) $\mathrm{J}$, heater leads (copper); K, jacket for sample container and heater cover (goldplated copper); L, pins for supporting sample container; $\mathbf{M}$, auxiliary heater for silver jacket (platinum): N, Inconel tubing; $\mathrm{O}$, alundum tube; $\mathrm{P}$, main furnace heater (platinum); Q, furnace insulation (silica powder); R, porcelain tube.

equality. In addition, $0.003 \mathrm{deg}$ also was added to correct for the error due to the estimated azimuthal temperature gradient in the silver pipe.

\section{Results and Conclusions}

The variation of temperature as the impure sodium melts may be predicted from Raoult's law. For very small proportions of impurities entirely insoluble in the solid solvent (sodium), this law may be written in the approximate form

$$
t=t_{0}-\left(R T_{0}^{2} / L_{f}\right)\left(x_{1}+x_{2}\right) .
$$

In this equation the total mole fraction of all solutes $\mathrm{n}$ solution in the liquid sodium has been divided into wo parts. $x_{1}$ designates that part due to solute hat, if present at all, is sufficient in amount to maintain the liquid sodium saturated with it. (This solute will be assumed to be uranium only.) $x_{2}$ designates that part due to any solute at all times entirely in solution in whatever liquid sodium is present; $t$ is the equilibrium temperature (in $\operatorname{deg} \mathrm{C}$ ); $t_{0}$ is the freezing (triple) point of pure sodium (also in deg C, the corresponding value in $\operatorname{deg} \mathrm{K}$ being $\left.T_{0}\right) ; R$ is the gas constant; and $L_{f}$ is the molal heat of fusion of sodium. 
It is evident that as fusion of the sodium progresses, the increasing amount of liquid available as solvent leads to a decrease of $x_{2}$ but not of $x_{1} . x_{2}$ may be replaced by its equivalent, $x_{2}^{\prime} / f$, where $f$ is the traction of the sodium present as liquid when the temperature is $t$, and $x_{2}^{\prime}$ is then the value of $x_{2}$ when $f$ is unity. Equation (1) then becomes

$$
t=t_{0}-R T_{0}^{2} x_{1} / L_{f}-\left(R T_{0}^{2} x_{2}^{\prime} / L_{f}\right)(1 / f) .
$$

Substituting numerical values for the known constants $\left(R=8.314 \mathrm{j} \mathrm{mole}^{-1} \mathrm{deg} \mathrm{K}^{-1}, T_{0}=371.0^{\circ} \mathrm{K}\right.$, and $\left.L_{f}=2603 \mathrm{j} \mathrm{mole}^{-1}\right),{ }^{2}$ eq (2) may be written in the present specific case as follows:

$$
t=t_{0}-440 x_{1}-440 x_{2}^{\prime}(1 / f) .
$$

The points in figure 2 show for various stages of fusion the individual observed equilibrium temperatures. The chronological number of each run is shown beside its respective points. It may be seen that for the same sample there is, in general, more variation from one run to another than in the systematic deviations from linearity of the points of one run. This is due partly to the errors in the calculated fractions melted, these errors arising chiefly from the difficulty of determining accurately when in each run fusion began and ended. The solubility of the steel container in the liquid sodium ${ }^{3}$ should have caused a constant error of less than $0.001 \mathrm{deg}$. This error has been ignored. Temperatures recorded when tusion was less than 70 or more than 98 percent complete were always decidedly too high to be in line with the others and were discarded. It seems likely that these latter discrepancies resulted partly from lack of the expected thermal and composition equilibrium, under these less favorable conditions, as the samples were neither shaken nor stirred. Also, the solubility of unidentified impurity may have been exceeded until a large fraction of the sodium had become molten.

Equation (3) predicts that as fusion progresses, the temperature will increase linearly with the decrease in $1 / f$. In figure 2 the straight line for each sample was obtained from the observed points by the method of least squares. The corresponding numerical values of the coefficients of eq (3), together with their standard deviations (precision), are shown in table 1. Several conclusions may be drawn from these values.

\begin{tabular}{|c|c|c|}
\hline Sample & $t_{0}-440 x_{1}$ & $440 x_{2}^{\prime}$ \\
\hline $\begin{array}{l}\mathrm{A} \\
\mathrm{B} \\
\mathrm{C}\end{array}$ & $\begin{array}{c}{ }^{\circ} \mathrm{C} \\
97.8199( \pm 0.0056) \\
97.8208( \pm 0.0033) \\
97.8202( \pm 0.0025)\end{array}$ & $\begin{array}{c}{ }^{\circ} \mathrm{C} \\
0.0349( \pm 0.0048) \\
.0379( \pm 0.0028) \\
.0297( \pm 0.0021)\end{array}$ \\
\hline
\end{tabular}

Table 1. Coefficients of equation (3) for three samples

2 D. C. Ginnings, T. B. Douglas, and A. F. Ball, J. Research NBS 45, 23 (1950) R P2110.

${ }^{3}$ L. F. Epstein (private communication).

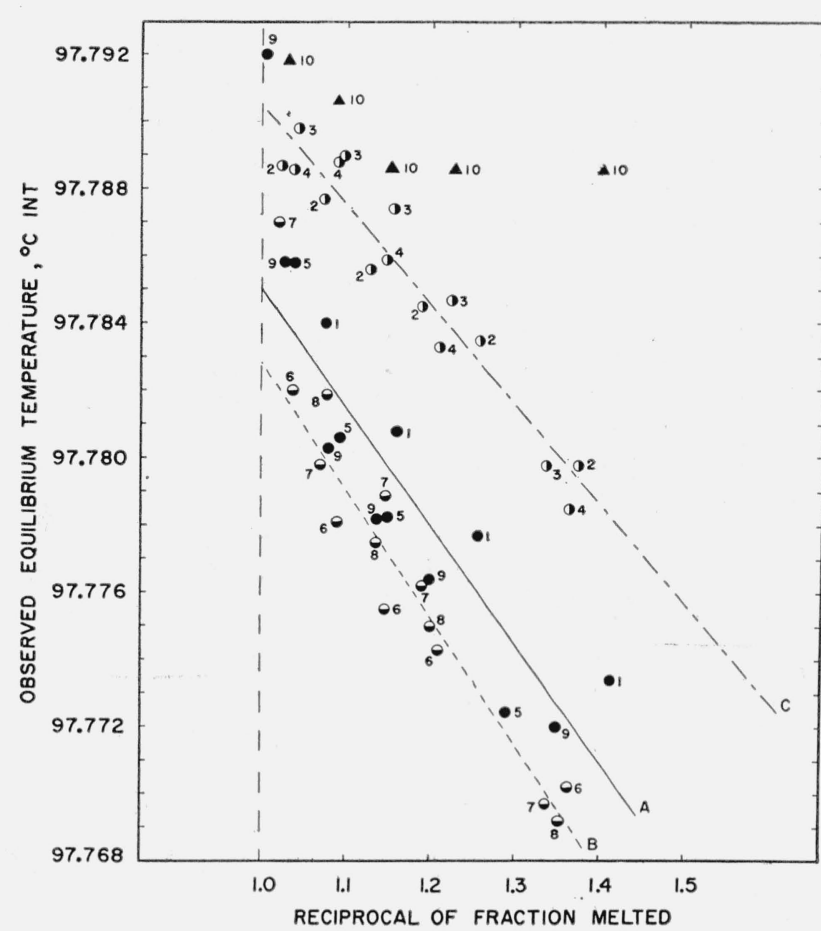

FIgURe 2. Observed equilibrium temperatures.

sample A (sodium); lus bulk uranium); uranium); $\boldsymbol{\Delta}$, sample D (an earlier sodium sample)

The run numbers given with the points are in chronological order.

From consideration of the details of purification of the sodium, it appears that the impurity with respect to which the liquid sodium was unsaturated may well have been largely sodium oxide, $\mathrm{Na}_{2} \mathrm{O}$. The values of the third column of table 1 give immediately the corresponding values of $x_{2}^{\prime}$, the mole fraction of this type of impurity in the whole sample. This averages $8 \times 10^{-5}$ for samples $A$ and $B$. This value corresponds to 0.02 percent of $\mathrm{Na}_{2} \mathrm{O}$ by weight, ${ }^{4}$ a reasonable amount of impurity from this source as it corresponds to the order of magnitude of the solubility of $\mathrm{Na}_{2} \mathrm{O}$ in liquid sodium at this temperature. The corresponding quantity for sample $\mathrm{C}$ is somewhat lower than that for sample $\mathrm{A}$, the difference having a standard deviation equal to the difference itself. It is possible that sample $\mathrm{C}$ actually contained substantially less impurity of this type, for the large surface of the finely divided uranium in this sample may have led to the removal of a considerable amount of the original impurity. Such a hypothesis is supported by the known ability of uranium to remove oxygen from $\mathrm{Na}_{2} \mathrm{O}$ at higher temperatures.

If it be assumed that sample $A$, into which no uranium had been introduced, was free of all other "saturated" solutes, the value of $t_{0}-440 x_{1}$ for this sample from table 1 gives $97.82^{\circ} \mathrm{C}$ as the triple point of pure sodium, and from a consideration of the

\footnotetext{
${ }^{4}$ If the effective molecular weight of $\mathrm{N}{ }_{2} \mathrm{O}$ be taken equal to its formula weight.
} 
various likely instrumental errors, this value is estimated to have an absolute accuracy of $\pm 0.02 \mathrm{deg}$. Earlier measurements on another sample of sodium, using a less stable copper resistance thermometer, had similarly yielded $97.80 \pm 0.03^{\circ} \mathrm{C}$ (see footnote 2 ).

The differences among the three values of the second column of table 1 will now be examined. Unless the uranium in samples B and $\mathrm{C}$ was completely protected from the sodium by some insoluble surface film, the values for these two samples should be lower than that for sample A by amounts $\left(440 x_{1}\right)$ corresponding to the solubility of uranium in liquid sodium at this temperature. ${ }^{5}$ These differences, with their standard deviations, are as follows: For sample $B, \quad 440 x_{1}=-0.0009^{\circ} \pm 0.0067^{\circ}$; and for sample C, $440 x_{1}=-0.0003^{\circ} \pm 0.0058^{\circ}$. These differences are thus zero within the precision of their measurement. The probability that the real differ-

${ }^{5}$ It seems very unlikely that uranium is appreciably soluble in solid sodium. ences exceed $0.02 \mathrm{deg}$ is very small. This figure would correspond to a value of $x_{1}$ of $5 \times 10^{-5}$, equivalent to 0.05 percent by weight of uranium dissolved in the liquid sodium if the dissolved uranium is monatomic. It is accordingly concluded from these measurements that the solubility of uranium in liquid sodium at $97.8^{\circ} \mathrm{C}$ probably lies between 0.00 and 0.05 percent.

It seems likely that a radioactive tracer method would furnish a more definite value for this solubility.

This work was supported by the Atomic Energy Commission. The author thanks C. E. Weber, of the Knolls Atomic Power Laboratory, Schenectady, N. Y., for supplying the sealed samples, and D. C. Ginnings, of the Bureau, for advice in designing part of the apparatus.

Washington, December 31, 1953. 